\title{
Modeling Spare Parts Demands Forecast under Two-Dimensional Preventive Maintenance Policy
}

\author{
Qiwei Hu, Yongsheng Bai, Jianmin Zhao, and Wenbin Cao \\ Department of Management Engineering, Mechanical Engineering College, Shijiazhuang 050003, China \\ Correspondence should be addressed to Qiwei Hu; h_q_w@sina.com
}

Received 20 October 2014; Revised 13 January 2015; Accepted 26 January 2015

Academic Editor: Mathieu Sellier

Copyright (C) 2015 Qiwei Hu et al. This is an open access article distributed under the Creative Commons Attribution License, which permits unrestricted use, distribution, and reproduction in any medium, provided the original work is properly cited.

\begin{abstract}
In maintenance practice, there is such a situation where the spare parts replacement should be carried out at the scheduling time of calendar or usage for whichever comes first. The issue of two-dimensional preventive maintenance usually was not addressed by traditional methods, and at present, few studies were focused on this very topic. Based on these considerations, this paper presented the two-dimensional preventive policy where replacements of spare parts are based on both calendar time and usage time. A novel model was developed to forecast spare parts demands under two-dimensional preventive maintenance policy, and a discrete algorithm was presented for solving the mathematical model. A case study was given to demonstrate its applicability and validity, and it was showed that the presented model can be used to forecast spare parts demands as well as to optimize spare parts and preventive maintenance jointly.
\end{abstract}

\section{Introduction}

Spare parts are common inventory stock items, which exist for satisfying the need of maintenance of plant systems [1]. Throughout plant life cycle costs, the expenditure on spare parts accounted for a large share. A study showed that, among the breakdown structures of plant life cycle cost, operational and maintenance support costs account for more than $60 \%$, of which spare parts costs account for $25 \sim 30 \%$. Meanwhile, spare parts inventory, spare parts allocation, and storage policy in a multiechelon inventory system have a great impact on the plant availability. Thereby, spare parts demands forecast is always one of the most critical issues in the research fields of maintenance support and logistics engineering.

Spare parts provision and planned maintenance are two related logistics activities, which must be considered together to achieve a cost effective and efficient logistics support. However, these two are often separately studied with few exceptions [2]. Generally, the traditional methods of forecasting spare parts demands are mostly for corrective maintenance other than preventive maintenance. Literatures [3-8] addressed the problems of failure-based repair policy and the connection with spare parts provision: [3] presented an optimum solution structure for an $n$-period repairable inventory problem; [4] presented a model of describing the station breakdown and repair rates as functions of the maintenance and repair inputs to the system; [5] modeled a two-echelon multi-indentured repairable-item inventory system where each "base" has a maximum number of identical online machines, and each machine consists of several module types, and machine failures are due to module failures and occur according to an exponential distribution as well; [7] concerned the problem of determining the optimal spare inventory level for a multiechelon repairable-item inventory system, which has several bases and a central depot. All of these papers considered how the inventory policy was affected by equipment failures rather than preventive maintenance. In recent years, several papers addressed the methods of forecasting spare parts demands and spare parts optimization considering both preventive maintenance and corrective maintenance $[2,9-16]$ : $[2,10]$ set up models to jointly optimize the spare parts inventory and the preventive maintenance inspection intervals; [9] presented a method which calculates the optimal time for preventive maintenance and spare part provision by a stochastic optimization algorithm based on a load-dependent reliability model; [11] addressed an inventory policy for spare parts, when demand for the spare parts arises due to regularly scheduled 
preventive maintenance, as well as random failure of units in service; [12] developed heuristics for the joint optimization of spare part inventory, maintenance frequency, and repair capacity for $k$-out-of- $N$ systems under both condition-based maintenance and block replacement; [13] proposed a simulation optimization approach based on genetic algorithms (GAs) for the joint optimization of preventive maintenance and spare provisioning policies of a manufacturing system operating in the automotive sector; [15] presented a method of joint optimization to establish an optimal production, delivery planning, and scheduling maintenance strategy for a manufacturing system; [16] proposed a jointly optimized age-based replacement and ordering policy using simulation. However, there is such a situation with which all of the above researches did not concern; namely, the preventive replacements of spare parts are based on both calendar time and usage time; for example, the replacement of tires for a car is carried out at the scheduling time of mileage over $60,000 \mathrm{~km}$ or 3 years of cumulative usage. Regardless of which condition comes first, the tires may be replaced with new ones. We define the preventive maintenance cycle for this situation as two-dimensional. Such products occupy a certain proportion of actual preventive maintenance projects. How to optimize spare parts under two-dimensional preventive maintenance policy (two-dimensional PM policy) has become a critical problem. But through analyzing the presented papers above, we can see that present research work on spare parts demands forecast has not considered the two-dimensional PM policy.

In the warranty research field, two-dimensional warranty, which is used to warranty policies optimization, has become a critical problem. The two-dimensional warranty is characterized by a region in a two-dimensional plane with one axis representing age and the other one usage. For instance, when you buy a new car, it usually comes with 3 years or 36,000 miles warranty, whichever comes first [17]. It is very similar to the two-dimensional PM policy. However, they are quite different indeed, and according to the literature [18-31], it can be concluded that the present research work on twodimensional warranty has not been jointed with spare parts demands forecast.

According to the above analysis, we can draw the conclusions that few studies were focused on modeling spare parts demands forecast under two-dimensional PM policy, and this area needs further attention either. Based on these considerations, this research was carried out choosing the nonrepairable spare parts for the object of study. The remainder of this paper is organized as follows: Section 2 discusses two-dimensional PM policy in detail; in Section 3, a novel model was developed to forecast spare parts demands under two-dimensional PM policy, and a discrete algorithm was presented for solving the mathematical model; a case study was given in Section 4; finally, Section 5 gives some concluding remarks and future research.

\section{Two-Dimensional PM Policy Descriptions}

The two-dimensional PM policy can be defined as a preventive maintenance policy that the item must be replaced by new one when its cumulative usage time reaches $U_{0}$

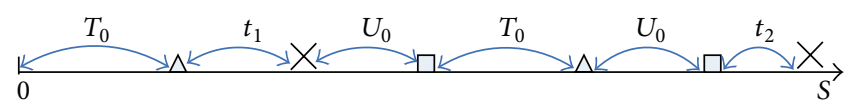

$\triangle$ Preventive replacement based on the calendar time $T_{0}$

$\square$ Preventive replacement based on the usage time $U_{0}$ X Failure replacement

FIGURE 1: Two-dimensional PM policy.

(e.g., mile, operational hour, turnaround, etc.) or its age is $T_{0}$ (calendar time, e.g., week, month, year, etc.). It can be illustrated in Figure 1.

In Figure 1, the preventive maintenance interval is twodimensional, namely, calendar time $T_{0}$ and usage time $U_{0}$. Whether the usage time reaches $U_{0}$ or the calendar time reaches $T_{0}$, the preventive replacement should be carried out. If product breaks down before reaching the scheduling time of $U_{0}$ and $T_{0}$, the failed item must be replaced by new one.

There is another term called two-dimensional warranty, which is similar to two-dimensional PM. From the literature [18], there are three main approaches to modeling failures for products sold with two-dimensional warranty.

Approach 1. In this approach, the time to first failure is modeled by a bivariate distribution function $F(t, u)$. If failed items are replaced by new ones and replacement times are negligible, then failures over the warranty region occur according to a two-dimensional renewal process [19-24].

Approach 2. In this approach, the two measures-age and usage-are combined to provide a single composite scale $Z$ (e.g., $Z=a t+b u$ and the failure process is modeled using this new composite scale $[25,26])$.

Approach 3. This approach assumes that the product usage rate $R$ varies from customer to customer, but it is a constant for a given customer. Then, it can be assumed that the usage rate $R$ is a random variable with given cumulative distribution function $F_{R}(r), 0 \leq r<\infty$ [27-31].

Through contrastive analysis, the differences between two-dimensional PM policy and two-dimensional warranty can be illustrated as follows.

(1) The definitions of the two terms are quite different, and their research emphases are different either.

(2) Two-dimensional warranty is used to warranty policies optimization, while two-dimensional PM policy is brought forward to forecast spare parts demands.

(3) Generally, most of present studies on two-dimensional warranty are concerned with corrective maintenance policy. However, because both preventive replacement and failure replacement generate the need of spare parts, two-dimensional PM policy is concerned with not only corrective maintenance but also preventive maintenance.

Because the preventive maintenance interval is twodimensional, there are three conditions for item replacement, 
that is, preventive replacement based on the calendar time $T_{0}$, preventive replacement based on the usage time $U_{0}$, and failure-based replacement. It is very difficult to model spare parts demands forecast under two-dimensional PM policy.

\section{Forecast Model and Solution Algorithm}

\subsection{Model Notations}

$T$ : Calendar time, for example, day, week, month, year, and so forth;

$U$ : Usage time of the product, for example, mile, kilometer, operational hour, turnaround, and so forth $\left(T_{0}, U_{0}\right)$ : Two-dimensional PM intervals, wherein $U_{0}$ is the replacement interval according to the usage time, while $T_{0}$ is the replacement interval according to the calendar time;

$S$ : Planning horizon, which is the calendar time;

$\operatorname{EN}\left(S, T_{0}, U_{0}\right)$ : The spare parts demands of the planning horizon $S$ under the two-dimensional PM intervals $\left(T_{0}, U_{0}\right)$;

$r$ : Usage rate of the product, which is illustrated as the ratio of usage time $T$ of the product to the calendar time $U$;

$f_{R}(r)$ : Probability density function of the usage rate $r$; $T_{p}, T_{f}$ : Mean time for a preventive replacement, mean time for a failure replacement, and then $T_{0}>T_{f}>T_{p}$;

$F(t), R(t), f(t)$ : The cumulative distribution function, reliability function, and probability density function of the first failure time of the item, respectively, and they are all the functions of calendar time $T$.

3.2. Modeling Two-Dimensional PM Policy. For the sake of calculation, the parameter of usage rate $r$ is introduced, which is illustrated as the ratio of usage time $T$ of the product to the calendar time $U$; we then have

$$
U=r \cdot T \text {. }
$$

Usage rate of a product is usually different from other products. Even for the same product, its usage rate will dynamically change along with time going; thus usage rate is the function of the calendar time $T$. If the planning horizon $S$ is too long, usage rate of a product will change remarkably. In this case, in order to forecast the spare parts demands, we should divide the planning horizon into several time segments $\left(S_{1}, S_{2}, \ldots, S_{n}\right)$ according to the usage rate. So the usage rate is approximately constant in each time segment $S_{i}$, and the problem of forecasting spare parts demands in the planning horizon $S$ will be transformed to calculate the spare parts demands of each time segment $S_{i}$.

For the nonrepairable spare parts, both corrective maintenance and preventive maintenance will generate the need of spare parts. As is shown in Figure 2, there is a straight line whose slope is $r_{0}$. It represents the situation that the usage time reaches $U_{0}$ while the calendar time reaches $T_{0}$, and there are two situations. (a) Preventive replacement based on calendar time $T_{0}$ : if $r_{1}<r_{0}$, it shows that the calendar time reaches $T_{0}$ before the usage time reaches $U_{0}$, so the preventive replacement should be performed according to the calendar time $T_{0}$.

(b) Preventive replacement based on operational time $U_{0}$ : on the contrary of the first situation, if $r_{2}>r_{0}$, it shows that the usage time reaches $U_{0}$ before the calendar time reaches $T_{0}$, so the preventive replacement should be performed according to the usage time $U_{0}$.

It is assumed that the item will be as good as new after the replacement. Then the clock tracking the item should be reset after either a failure-based replacement or a preventive replacement.

Through the above analysis of two-dimensional PM policy, the relation between $U$ and $T$ was constructed by the parameter of usage rate $r$. If $r$ is constant in the planning horizon $S$, the situations of generating spare parts demands can be divided into the following three cases.

(1) When $0 \leq S \leq T_{f}$, no replacement is carried out. Firstly, the item should not be replaced even if it fails, because replacement of the failed item cannot be finished before reaching time $S$. Secondly, because $T_{0}>T_{f} \geq S$, there is no preventive replacement based on the calendar time. At last, it is impossible that the usage rate $r$ is so high in a short period of time $S$ that the usage time reaches the value of $U_{0}$. So there is no preventive replacement based on the usage time $U_{0}$ either. In conclusion, when $0 \leq S \leq T_{f}$, there is no replacement carried out and no need of the spare parts.

(2) Only failure-based replacement is carried out. From the above analysis of two-dimensional PM policy, we can conclude that preventive replacement has two cases according to the parameter $r$.

(i) If $r<r_{0}$, preventive replacement is carried out according to $T_{0}$. In this case, when $T_{f}<S \leq$ $T_{0}+T_{f}$, preventive replacement should not be carried out even if the calendar time reaches $T_{0}$.

(ii) If $r \geq r_{0}$, preventive replacement is carried out according to $U_{0}$. In this case, when $T_{f}<S \leq$ $U_{0} / r+T_{f}$, preventive replacement should not be carried out even if the usage time reaches $U_{0}$.

In both the above cases, if the item fails at the time close to $S$, we can hardly restore the function of the failed item in a short time. Therefore, only when the item fails before $S-T_{f}$, failure-based replacement will be carried out. The spare parts demands lie on failurebased replacement in this case.

(3) Both preventive replacement and failure-based replacement are carried out. When $r<r_{0}$ and $S>$ $T_{0}+T_{f}$ or $r \geq r_{0}$ and $S>U_{0} / r+T_{f}$, failurebased replacement is carried out after a failure occurs before $S-T_{f}$, and preventive replacement is carried out after the usage time reaches $U_{0}$ or the calendar 


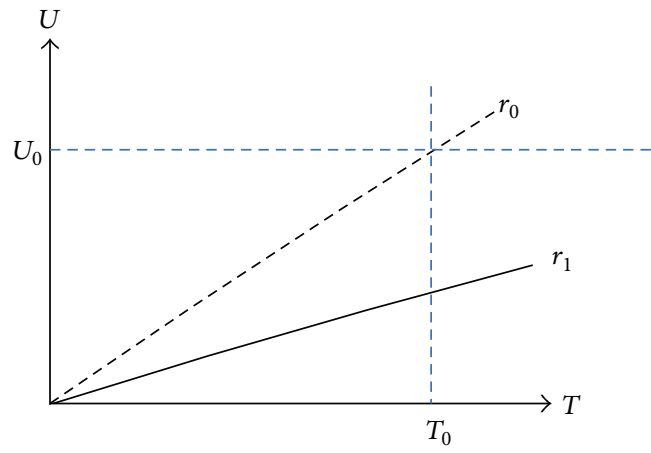

(a) Preventive replacement based on calendar time $T_{0}$

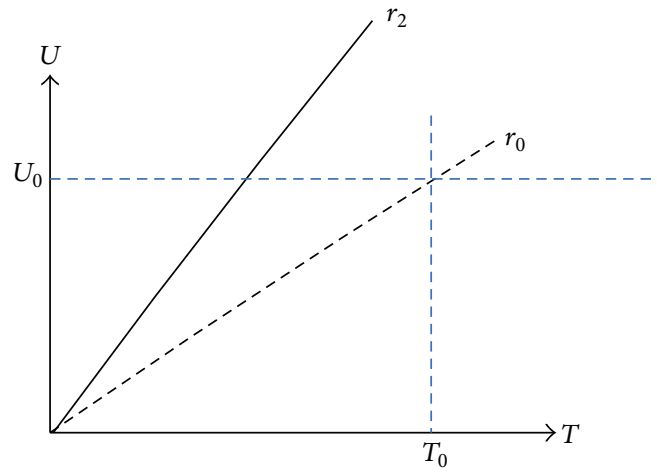

(b) Preventive replacement based on usage time $U_{0}$

FIgURE 2: Analysis of two-dimensional PM policy.

time reaches $T_{0}$. In this case, the spare parts demands lie on both failure-based replacement and preventive replacement.

3.3. Modeling Spare Parts Demands. According to the above analysis results, the model of forecasting spare parts demands under two-dimensional PM policy was developed in the following cases.

3.3.1. Case A: Spare Parts Demands for $0 \leq S \leq T_{f}$. According to the above analysis result (1), when $0 \leq S \leq T_{f}$, there is no need of spare parts, and then we have the function of $\mathrm{EN}\left(S, T_{0}, U_{0}\right)$ in case of $0 \leq S \leq T_{f}$ :

$$
\operatorname{EN}\left(S, T_{0}, U_{0}\right)=0 .
$$

3.3.2. Case B: Spare Parts Demands for $T_{f}<S \leq T_{0}+T_{f}$. According to the above analysis result (2), there are two cases.

(1) When $r<r_{0}$, the need of spare parts is only generated by the failures. In other words, the spare parts demands in this case are equal to the number of the failure-based replacement. According to the renewal process model [32], we have the function of $\mathrm{EN}\left(S, T_{0}, U_{0}\right)$ in this case:

$$
\begin{aligned}
& \operatorname{EN}\left(S, T_{0}, U_{0}\right) \\
& =\int_{0}^{S-T_{f}}\left[1+\mathrm{EN}\left(S-t-T_{f}, T_{0}, U_{0}\right)\right] \cdot f(t) d t, \\
& r<r_{0} .
\end{aligned}
$$

(2) When $r \geq r_{0}$, preventive replacement should be carried out according to the usage time $U_{0}$. However, not all of the cases follow this rule. As is shown in Figure 3 , there is a critical value $r_{m}$, where $U_{0} / r_{m}=$ $S-T_{f}$.

According to the above analysis result (2), when $r_{0} \leq r \leq$ $r_{m}$ (i.e., the straight line of which the slope is $r_{1}$ ), because $T_{1} \geq$ $S-T_{f}$, there is no need of spare parts generated by preventive

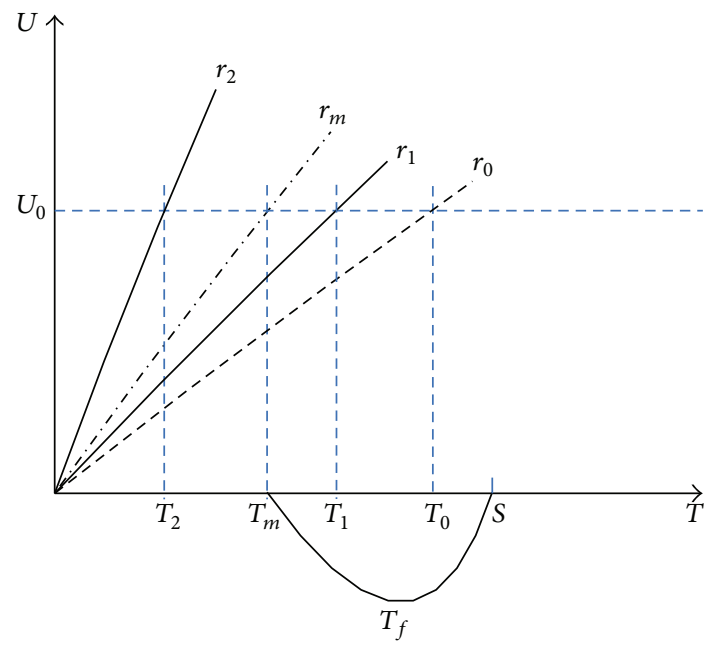

FIGURE 3: Analysis of preventive replacement based on usage time $U_{0}$.

replacement. When $r>r_{m}$ (i.e., the straight line of which the slope is $r_{2}$ ), because $T_{2}<S-T_{f}$, preventive replacement is carried out according to $U_{0}$, and the need of spare parts is generated according to the usage time $U_{0}$. So we can draw the conclusion that when $r \leq r_{m}$, the need of spare parts is only generated by failure-based replacement; when $r>r_{m}$, the need of spare parts is generated by either failure-based replacement or preventive replacement based on usage time $U_{0}$. Then we have the function of $\operatorname{EN}\left(S, T_{0}, U_{0}\right)$ in this case:

$$
\begin{aligned}
& \operatorname{EN}\left(S, T_{0}, U_{0}\right) \\
& = \begin{cases}\int_{0}^{S-T_{f}}\left[1+\mathrm{EN}\left(S-t-T_{f}, T_{0}, U_{0}\right)\right] \cdot f(t) d t, & r \leq r_{m} \\
\int_{0}^{U_{0} / r}\left[1+\mathrm{EN}\left(S-t-T_{f}, T_{0}, U_{0}\right)\right] \cdot f(t) d t & \\
+\left[1+\mathrm{EN}\left(S-\frac{U_{0}}{r}-T_{p}, T_{0}, U_{0}\right)\right] \cdot R\left(\frac{U_{0}}{r}\right), & r>r_{m} .\end{cases}
\end{aligned}
$$


Because $f_{R}(r)$ is a probability density function of the parameter $r$, formula (4) becomes the following function:

$$
\begin{aligned}
& \operatorname{EN}\left(S, T_{0}, U_{0}\right) \\
& \begin{array}{l}
\int_{0}^{r_{m}} \int_{0}^{S-T_{f}}\left[1+\mathrm{EN}\left(S-t-T_{f}, T_{0}, U_{0}\right)\right] \\
\cdot f(t) \cdot f_{R}(r) d t d r \\
+\int_{r_{m}}^{+\infty}\left\{\int_{0}^{U_{0} / r}\left[1+\mathrm{EN}\left(S-t-T_{f}, T_{0}, U_{0}\right)\right] \cdot f(t) d t\right. \\
\left.+\left[1+\mathrm{EN}\left(S-\frac{U_{0}}{r}-T_{p}, T_{0}, U_{0}\right)\right] \cdot R\left(\frac{U_{0}}{r}\right)\right\} \\
\cdot f_{R}(r) d r .
\end{array}
\end{aligned}
$$

Because $U_{0} / r_{m}=S-T_{f}, r_{m}$ in formula (5) can be calculated by the following formula:

$$
r_{m}=\frac{U_{0}}{\left(S-T_{f}\right)} .
$$

3.3.3. Case C: Spare Parts Demands for $S>T_{0}+T_{f}$. According to the above analysis result (3), when $S>T_{0}+T_{f}$, both preventive replacement and failure-based replacement exist simultaneously regardless of the parameter $r$.

(1) When $r<r_{0}$, there are failure-based replacement and preventive replacement based on calendar time $T_{0}$. Then we have the function of forecasting spare parts demands in this case:

$$
\begin{aligned}
\operatorname{EN} & \left(S, T_{0}, U_{0}\right) \\
= & \int_{0}^{T_{0}}\left[1+\operatorname{EN}\left(S-t-T_{f}, T_{0}, U_{0}\right)\right] \cdot f(t) d t \\
& +\left[1+\operatorname{EN}\left(S-T_{0}-T_{p}, T_{0}, U_{0}\right)\right] \cdot R\left(T_{0}\right), \quad r<r_{0} .
\end{aligned}
$$

(2) When $r \geq r_{0}$, there are failure-based replacement and preventive replacement according to usage time $U_{0}$. The need of spare parts in this case can be calculated by the following function:

$$
\begin{aligned}
\operatorname{EN} & \left(S, T_{0}, U_{0}\right) \\
= & \int_{0}^{U_{0} / r}\left[1+\mathrm{EN}\left(S-t-T_{f}, T_{0}, U_{0}\right)\right] \cdot f(t) d t \\
& +\left[1+\mathrm{EN}\left(S-\frac{U_{0}}{r}-T_{p}, T_{0}, U_{0}\right)\right] \cdot R\left(\frac{U_{0}}{r}\right), \quad r \geq r_{0} .
\end{aligned}
$$

Similarly, because $f_{R}(r)$ is probability density function of the parameter $r$, formulas (7) and (8) are integrated to a function, and we then have

$$
\begin{aligned}
& \operatorname{EN}\left(S, T_{0}, U_{0}\right) \\
& =\int_{0}^{r_{0}}\left\{\int_{0}^{T_{0}}\left[1+\mathrm{EN}\left(S-t-T_{f}, T_{0}, U_{0}\right)\right] \cdot f(t) d t\right. \\
& \left.+\left[1+\mathrm{EN}\left(S-T_{0}-T_{p}, T_{0}, U_{0}\right)\right] \cdot R\left(T_{0}\right)\right\} \\
& +f_{R}(r) d r \\
& +\int_{r_{0}}^{+\infty}\left\{\int_{0}^{U_{0} / r}\left[1+\mathrm{EN}\left(S-t-T_{f}, T_{0}, U_{0}\right)\right] \cdot f(t) d t\right. \\
& \left.+\left[1+\mathrm{EN}\left(S-\frac{U_{0}}{r}-T_{p}, T_{0}, U_{0}\right)\right] \cdot R\left(\frac{U_{0}}{r}\right)\right\} \\
& \cdot f_{R}(r) d r .
\end{aligned}
$$

Based on the above models constructed in three cases, we can integrate formulas (2), (5), and (9) to the function of forecasting spare parts demands under two-dimensional PM policy:

$\operatorname{EN}\left(S, T_{0}, U_{0}\right)$

$$
\begin{aligned}
& \left\{\begin{array}{c}
\int_{0} \int_{0}^{r_{m}} \quad 0 \leq S \leq T_{f}, \\
\cdot f(t) d t \cdot f_{R}(r) d r \\
+\int_{r_{m}}^{+\infty}\left\{\int_{0}^{U_{0} / r}\left[1+\mathrm{EN}\left(S-t-T_{f}, T_{0}, U_{0}\right)\right]\right. \\
\cdot f(t) d t \\
\quad+\left[1+\mathrm{EN}\left(S-\frac{U_{0}}{r}-T_{p}, T_{0}, U_{0}\right)\right] \\
\left.\cdot R\left(\frac{U_{0}}{r}\right)\right\} \\
\cdot f_{R}(r) d r, \quad T_{f}<S \leq T_{0}+T_{f}, \\
\int_{0}^{r_{0}} \int_{0}^{T_{0}}\left[1+\mathrm{EN}\left(S-t-T_{f}, T_{0}, U_{0}\right)\right] \cdot f(t) d t \\
+\left[1+\mathrm{EN}\left(S-T_{0}-T_{p}, T_{0}, U_{0}\right)\right] \cdot R\left(T_{0}\right) \\
\cdot f_{R}(r) d r \\
+\infty
\end{array}\right. \\
& +\left[1+\mathrm{EN}\left(S-\frac{U_{0}}{r}-T_{p}, T_{0}, U_{0}\right)\right] \\
& \left.\cdot R\left(\frac{U_{0}}{r}\right)\right\} \\
& \cdot f_{R}(r) d r, \quad S>T_{0}+T_{f} \text {. }
\end{aligned}
$$


3.4. Discrete Algorithm for the Model Solution. From the equations deduced above, it can be seen that the model is very difficult to solve directly because of its recurrence relation. Hence, the thought of numerical calculation was adopted, the discrete algorithm [33] was introduced, and the calculation process for spare parts demand was given.

Step 1. Judge if $S$ is longer than $T_{f}$. From the analysis above, it is obvious that when $0 \leq S \leq T_{f}$, the value of $\operatorname{EN}\left(S, T_{0}, U_{0}\right)$ is zero; that is, $\operatorname{EN}\left(0, T_{0}, U_{0}\right), \operatorname{EN}\left(1, T_{0}, U_{0}\right), \ldots, \operatorname{EN}\left(T_{f}, T_{0}, U_{0}\right)$ are all equal to 0 . When $S>T_{f}$, it should go to Step 2 .

Step 2. When $T_{f}<S \leq T_{0}+T_{f}$, discretize the failure time $t$ by step $\Delta t$ according to the specific requirements and calculate the value of (3).

For example, if the discrete steps for $\Delta t$ were taken as "1," then the definite integral for $t$ can be discretized as follows:

$$
\begin{aligned}
& \int_{0}^{S-T_{f}}\left[1+\mathrm{EN}\left(S-t-T_{f}, T_{0}, U_{0}\right)\right] \cdot f(t) d t \\
& =\int_{0}^{1} f(t) d t \cdot\left[1+\mathrm{EN}\left(S-1-T_{f}, T_{0}, U_{0}\right)\right] \\
& \quad+\int_{1}^{2} f(t) d t \cdot\left[1+\mathrm{EN}\left(S-2-T_{f}, T_{0}, U_{0}\right)\right] \\
& \quad+\cdots+\int_{S-2 T_{f}-1}^{S-2 T_{f}} f(t) d t \cdot\left[1+\operatorname{EN}\left(T_{f}, T_{0}, U_{0}\right)\right] \\
& \quad+\cdots+\int_{S-T_{f}-1}^{S-T_{f}} f(t) d t \cdot\left[1+\operatorname{EN}\left(0, T_{0}, U_{0}\right)\right]
\end{aligned}
$$

Step 3. For a given $r$, discretize the failure time $t$ in the same way. For example, if the discrete steps for $\Delta t$ were still taken as "1," then the definite integral can be discretized as follows:

$$
\begin{aligned}
& \int_{0}^{U_{0} / r}\left[1+\mathrm{EN}\left(S-t-T_{f}, T_{0}, U_{0}\right)\right] \cdot f(t) d t \\
& =\int_{0}^{1} f(t) d t \cdot\left[1+\mathrm{EN}\left(S-1-T_{f}, T_{0}, U_{0}\right)\right] \\
& \quad+\int_{1}^{2} f(t) d t \cdot\left[1+\operatorname{EN}\left(S-2-T_{f}, T_{0}, U_{0}\right)\right] \\
& \quad+\cdots+\int_{U_{0} / r-1}^{U_{0} / r} f(t) d t \cdot\left[1+\operatorname{EN}\left(0, T_{0}, U_{0}\right)\right]
\end{aligned}
$$

Step 4. Discretize the usage rate $r$ by step $\Delta r$ according to the specific requirements and calculate the finite integral for $r$ with the probability density distribution of $f_{R}(r)$. Then the value of $\operatorname{EN}\left(S, T_{0}, U_{0}\right)$ can be recurred.

Step 5. When $S>T_{0}+T_{f}$, the value of $\operatorname{EN}\left(S, T_{0}, U_{0}\right)$ can be got likewise from Step 2 to Step 4. The major difference is that the upper integral bound for $t$ becomes $T_{0}$ from $S-T_{f}$.

Thus, the expectation of spare parts demand in a planning horizon $S$ can be solved by discrete algorithm, on condition
TABLE 1: The parameter values of the usage rate function for different usage types.

\begin{tabular}{lccc}
\hline Usage type & $a_{r}$ & $\beta_{r}(\mathrm{~km} /$ day $)$ & $r_{\max }(\mathrm{km} /$ day $)$ \\
\hline Low usage rate & 3.51 & 31 & 200 \\
Moderate usage rate & 3.45 & 52 & 400 \\
High usage rate & 3.67 & 83 & 600 \\
\hline
\end{tabular}

that the two-dimensional preventive replacement intervals $\left(T_{0}, U_{0}\right)$ are known.

\section{Case Study}

In order to demonstrate the applicability and validity of the model of forecasting spare parts demands, a type of automobile was taken as an example to conduct a case study. It is quite reasonable that the automobile was chosen as the object of the case study mainly because (a) preventive replacements of many components and parts of the automobile, for example, tires, oil filters, sparking plugs, and so on, are based on both calendar time and usage time; (b) most automobiles are driven at a constant usage rate over a period of time, and then the accumulative mileage can be expressed as an increasing linear equation of the calendar time, which satisfies the requirements of the model presented in this paper; (c) we can gain enough operational and maintenance data from the car service shop to support the case study.

The latest two years' operational and maintenance records for a type of automobile (FAW-Volkswagen, Sagitar 1.6 L) were collected from a car service shop. Before carrying out the case study, analysis of operational and maintenance data had been conducted, and the conclusion was that the usage rate remarkably varied from user to user. For example, a user like a housewife usually has a low usage rate of the automobile, a user like a common staff has a moderate usage rate, and a driver like a taximan has a high usage rate. Therefore, in order to consider different situations in the case study, we divided the overall records into three types according to the usage rate, that is, low usage rate, moderate usage rate, and high usage rate.

For the sake of determining the distribution of the usage rate, we conducted fitting of distribution according to the history usage data, and we found that it follows the Weibull distribution:

$$
f_{R}(r)=\frac{a_{r}}{\beta_{r}}\left(\frac{r}{\beta_{r}}\right)^{a_{r}-1} e^{-\left(r / \beta_{r}\right)^{a_{r}}} .
$$

The maximum likelihood estimation (MLE) was adopted to estimate the parameters in the usage rate function (13), and then we can get the parameter estimation results shown in Table 1. Besides, we investigated different users for more information about the usage rate of their automobiles, and then we got the mean value of the maximum usage rate for different usage types shown in Table 1 either.

In the following case study, we only chose the oil filter of the automobile as the representative research object because there were numerous operational and maintenance records in 
TABLE 2: The need for oil filter under three usage types in a year.

\begin{tabular}{lccc}
\hline & Low usage rate & Moderate usage rate & High usage rate \\
\hline $\begin{array}{l}\text { Need for } \\
\text { oil filter }\end{array}$ & 1.390 & 0.562 & 1.861 \\
\hline
\end{tabular}

the car service shop. Assume that the first failure time for the oil filter follows Weibull distribution, and then the parameters can be estimated in the same way; that is, $\alpha_{t}=3.24, \beta_{t}=6.85$ months. From the maintenance records, we also estimated the other parameters of the forecasting model of the spare parts demands; that is, $T_{p}=2$ days, $T_{f}=7$ days.

Based on the above conditions, an integrated case was conducted to forecast spare parts demands, as well as to optimize spare parts and two-dimensional PM policy jointly.

\subsection{Forecasting Spare Parts Demand under Given Preventive} Replacement Interval. According to the service manual of this automobile, the preventive replacement interval of the oil filter is $(6$ months, $5000 \mathrm{~km})$; namely, $T_{0}=6$ months, $U_{0}=5000 \mathrm{~km}$. In this situation, based on the forecast model presented in the paper and the above parameter values, we can easily calculate the need for the oil filter in any given planning horizon $S$. When $S=12$ months, we got the forecast results under the three usage types as shown in Table 2.

From the results shown in Table 2, we can see the following.

First of all, the need for oil filter is less under "moderate usage rate" than the other two circumstances. Therefore, in order to reduce the maintenance cost under a given preventive replacement interval, it is obvious that the optimized usage way for the automobile is based on moderate usage rate. Actually, the results are consistent with the actual conditions because the preventive replacement interval was optimized under some nominal usage rate $r_{0}$.

What is more, the preventive replacement interval under the nominal usage rate is not adapted to all of the conditions. For example, if the preventive replacement interval was optimal for all of the three usage types, the need for oil filter under "low usage rate" would presumably be less than that under "moderate usage rate." Therefore, the preventive replacement interval should be further optimized.

To sum up, when we determine the preventive replacement interval, we should consider the variation of the usage rate for different users and carry out a joint optimization of spare parts and preventive replacement.

\subsection{Joint Optimization of Spare Parts and Preventive Replace-} ment. Further to the above case, considering the circumstances are all the same, we carried out a joint optimization of spare parts and preventive replacement.

Assume that the usage time-based preventive replacement interval of the oil filter is unknown, and the calendar time-based preventive replacement interval was determined according to its storage life; that is, $T_{0}=6$ months. The problem is to jointly optimize the usage time-based preventive replacement and spare parts. Then we used the model proposed in the paper to conduct the joint optimization, and

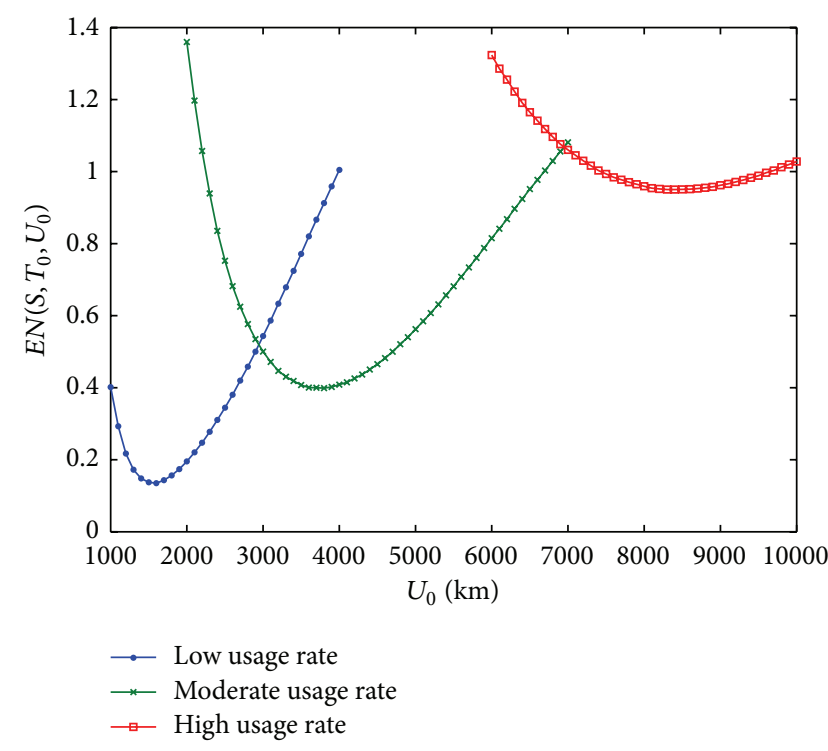

FIGURE 4: Development of spare parts demand for different usage time-based preventive replacement intervals under three different usage types.

the optimization results are shown in Figure 4. We can see that the joint optimization result for spare parts and preventive replacement is different under different usage types: (a) when the usage type is "low usage rate," the optimized $U_{0}$ is $1600 \mathrm{~km}$, and EN (1 year, 6 months, $1600 \mathrm{~km})=0.135$; (b) when the usage type is "moderate usage rate," the optimized $U_{0}$ is $3800 \mathrm{~km}$, and EN (1 year, 6 months, $3800 \mathrm{~km}$ ) $=0.399$; (c) when the usage type is "high usage rate," the optimized $U_{0}$ is $8300 \mathrm{~km}$, and the need of the spare parts EN (1 year, 6 months, $8300 \mathrm{~km})=0.950$.

From the above numerical experiment results, we can conclude the following.

Firstly, under different usage rates, the optimal preventive replacement interval and spare parts demand vary significantly. Specifically, with the increase of usage rate, the optimal usage replacement interval becomes longer, and the spare parts demand under optimal preventive replacement interval becomes greater. It means that the more frequently the automobile is used, the worse it becomes, and the more spare parts are needed.

Secondly, the model presented in the paper is used not only to forecast spare parts demands, but also to optimize spare parts and preventive maintenance jointly. By contrast, we can see that the spare parts demands after optimizing the preventive maintenance are less than those before optimization. The comparison results are shown in Table 3. It showed that the optimization is effective.

Thirdly, when preventive replacement for a product is two-dimensional, the preventive replacement interval should be determined based on the usage rate for the product. In particular when the usage rate varies significantly for different users, we should differentiate varied usage types to determine the preventive maintenance interval for seeking least spare parts cost. 
TABLE 3: The comparison between the forecast results and optimization results.

\begin{tabular}{lcc}
\hline Usage type & $\begin{array}{c}\text { Need for oil filter } \\
\text { before optimization }\end{array}$ & $\begin{array}{c}\text { Need for oil filter } \\
\text { after optimization }\end{array}$ \\
\hline Low usage rate & 1.390 & $>0.135$ \\
Moderate usage rate & 0.562 & $>0.399$ \\
High usage rate & 1.861 & $>0.950$ \\
\hline
\end{tabular}

\section{Conclusions and Future Research}

The shortage of spare parts needed when carrying out maintenance is a critical problem for many industrial organizations. If there is lack of spare parts, it may take several days for waiting the spare parts and this will extend the downtime of the equipment with significant costs. In order to deal with the problem, a cost effective solution is to consider spare parts and maintenance jointly. But, most of the present works played emphasis on the one-dimensional preventive maintenance, namely, usage time-based preventive maintenance and corrective maintenance.

In this paper, we concentrated on the issue of twodimensional PM policy, and a novel model was developed to forecast spare parts demands under this policy. A discrete algorithm was presented for solving the mathematical model. A case study was given to demonstrate its applicability and validity. Besides, a few of conclusions were drawn from the numerical experiment results and may benefit the works for determining two-dimensional preventive replacement interval and optimizing spare parts and preventive maintenance jointly.

Aside from the topic in the paper, it must be pointed out that there are still several other topics for further research in the future as follows.

Firstly, there is usually more than one objective for optimization of spare parts and preventive maintenance, such as high availability and low costs. This paper only presents a one-objective optimization model, and a multiobjective approach needs to be established.

Secondly, this research was carried out under the circumstance of choosing the nonrepairable spare parts for the object of study. The model of forecasting repairable spare parts demands under two-dimensional PM policy needs to be developed.

Last but not least, there are two types of preventive replacement, that is, age-based replacement and block-based replacement. The two-dimensional PM policy presented in the paper was established based on age-based replacement. If the block-based replacement is introduced to the twodimensional PM policy, the issue will be changed, and it needs further study on the model of forecasting spare parts demands.

\section{Conflict of Interests}

The authors declare that there is no conflict of interests regarding the publication of this paper.

\section{References}

[1] W. J. Kennedy, J. Wayne Patterson, and L. D. Fredendall, "An overview of recent literature on spare parts inventories," International Journal of Production Economics, vol. 76, no. 2, pp. 201-215, 2002.

[2] W. Wang, "A joint spare part and maintenance inspection optimisation model using the Delay-Time concept," Reliability Engineering and System Safety, vol. 96, no. 11, pp. 1535-1541, 2011.

[3] V. P. Simpson, "Optimum solution structure for a repairable inventory problem," Operations Research, vol. 26, no. 2, pp. 270281, 1978.

[4] S. Yeralan, A. J. Dieck, and R. F. Darwin, "Economically optimum maintenance, repair and buffering operations in manufacturing systems," The Engineering Economist, vol. 31, no. 4, pp. 279-292, 1986.

[5] S. C. Albright and A. Gupta, "Steady-state approximation of a multiechelon multi-indentured repairable-item inventory system with a single repair facility," Naval Research Logistics, vol. 40, no. 4, pp. 479-493, 1993.

[6] T. S. Dhakar, C. P. Schmidt, and D. M. Miller, "Base stock level determination for high cost low demand critical repairable spares," Computers and Operations Research, vol. 21, no. 4, pp. 411-420, 1994.

[7] J.-S. Kim, K.-C. Shin, and H.-K. Yu, "Optimal algorithm to determine the spare inventory level for a repairable-item inventory system," Computers and Operations Research, vol. 23, no. 3, pp. 289-297, 1996.

[8] M. Finkelstein, "On systems with shared resources and optimal switching strategies," Reliability Engineering \& System Safety, vol. 94, no. 8, pp. 1358-1362, 2009.

[9] G. Lanza, S. Niggeschmidt, and P. Werner, "Optimization of preventive maintenance and spare part provision for machine tools based on variable operational conditions," CIRP AnnalsManufacturing Technology, vol. 58, no. 1, pp. 429-432, 2009.

[10] W. Wang, "A stochastic model for joint spare parts inventory and planned maintenance optimisation," European Journal of Operational Research, vol. 216, no. 1, pp. 127-139, 2012.

[11] T. S. Vaughan, "Failure replacement and preventive maintenance spare parts ordering policy," European Journal of Operational Research, vol. 161, no. 1, pp. 183-190, 2005.

[12] K. S. de Smidt-Destombes, M. C. van der Heijden, and A. van Harten, "Joint optimisation of spare part inventory, maintenance frequency and repair capacity for $k$-out-of- $N$ systems," International Journal of Production Economics, vol. 118, no. 1, pp. 260-268, 2009.

[13] M. A. Ilgin and S. Tunali, "Joint optimization of spare parts inventory and maintenance policies using genetic algorithms," International Journal of Advanced Manufacturing Technology, vol. 34, no. 5-6, pp. 594-604, 2007.

[14] W. Wang and A. A. Syntetos, "Spare parts demand: linking forecasting to equipment maintenance," Transportation Research Part E: Logistics and Transportation Review, vol. 47, no. 6, pp. 1194-1209, 2011.

[15] S. Turki, Z. Hajej, and N. Rezg, "Impact of delivery time on optimal production/delivery/maintenance plans," in Proceedings of the 8th IEEE International Conference on Automation Science and Engineering (CASE '12), Seoul, Republic of Korea, 2012.

[16] A. B. M. Z. Kabir and A. S. Al-Olayan, "A stocking policy for spare part provisioning under age based preventive replacement," European Journal of Operational Research, vol. 90, no. 1, pp. 171-181, 1996. 
[17] T. Chen and E. Popova, "Maintenance policies with twodimensional warranty," Reliability Engineering and System Safety, vol. 77, no. 1, pp. 61-69, 2002.

[18] M. Shafiee, S. Chukova, M. Saidi-Mehrabad, and S. T. A. Niaki, "Two-dimensional warranty cost analysis for second-hand products," Communications in Statistics-Theory and Methods, vol. 40, no. 4, pp. 684-701, 2011.

[19] H.-G. Kim and B. M. Rao, "Expected warranty cost of twoattribute free-replacement warranties based on a bivariate exponential distribution," Computers and Industrial Engineering, vol. 38, no. 4, pp. 425-434, 2000.

[20] S.-C. Yang and J. A. Nachlas, "Bivariate reliability and availability modeling," IEEE Transactions on Reliability, vol. 50, no. 1, pp. 26-35, 2001.

[21] S. Pal and G. S. R. Murthy, "An application of Gumbel's bivariate exponential distribution in estimation of warranty cost of motor cycles," International Journal of Quality \& Reliability Management, vol. 20, no. 4, pp. 488-502, 2003.

[22] J. Baik, D. N. P. Murthy, and N. Jack, "Two-dimensional failure modeling with minimal repair," Naval Research Logistics, vol. 51, no. 3, pp. 345-362, 2004.

[23] M. Jung and D. S. Bai, "Analysis of field data under twodimensional warranty," Reliability Engineering and System Safety, vol. 92, no. 2, pp. 135-143, 2007.

[24] C. Dinu, C. Stefanka, and O. Jason, "Product warranty: modelling with 2D-renewal process," International Journal of Reliability and Safety, vol. 2, no. 3, pp. 209-220, 2008.

[25] I. B. Gertsbakh and K. B. Kordonsky, "Parallel time scales and two-dimensional manufacturer and individual customer warranties," IIE Transactions, vol. 30, no. 12, pp. 1181-1189, 1998.

[26] T. Duchesne and J. F. Lawless, "Alternative time scales and failure time models," Lifetime Data Analysis, vol. 6, no. 2, pp. 157-179, 2000.

[27] Y. H. Chun and K. Tang, "Cost analysis of two-attribute warranty policies based on the product usage rate," IEEE Transactions on Engineering Management, vol. 46, no. 2, pp. 201209, 1999.

[28] B. Rai and N. Singh, "A modeling framework for assessing the impact of new time/mileage warranty limits on the number and cost of automotive warranty claims," Reliability Engineering and System Safety, vol. 88, no. 2, pp. 157-169, 2005.

[29] D. K. Manna, S. Pal, and S. Sinha, "Optimal determination of warranty region for 2D policy: a customers' perspective," Computers \& Industrial Engineering, vol. 50, no. 1-2, pp. 161-174, 2006.

[30] S. Chukova and M. R. Johnston, "Two-dimensional warranty repair strategy based on minimal and complete repairs," Mathematical and Computer Modelling, vol. 44, no. 11-12, pp. 1133-1143, 2006.

[31] N. Jack, B. P. Iskandar, and D. N. P. Murthy, "A repairreplace strategy based on usage rate for items sold with a two-dimensional warranty," Reliability Engineering and System Safety, vol. 94, no. 2, pp. 611-617, 2009.

[32] X. Jia, The Decision Models for Reliability Centered Maintenance, National Defense Industry Press, Beijing, China, 2007.

[33] Jardine, Maintenance, Replacement and Reliability, Mechanical Industry Press, Beijing, China, 1985. 


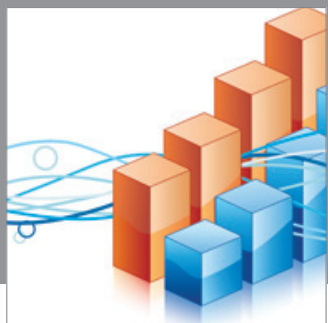

Advances in

Operations Research

mansans

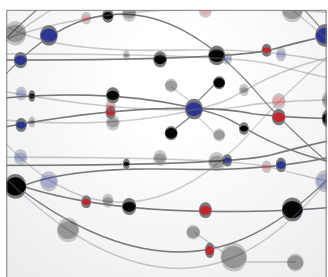

The Scientific World Journal
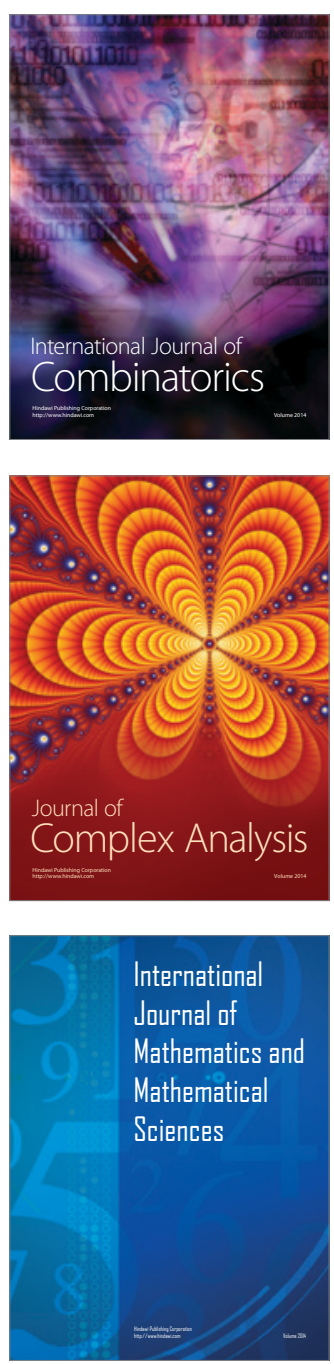
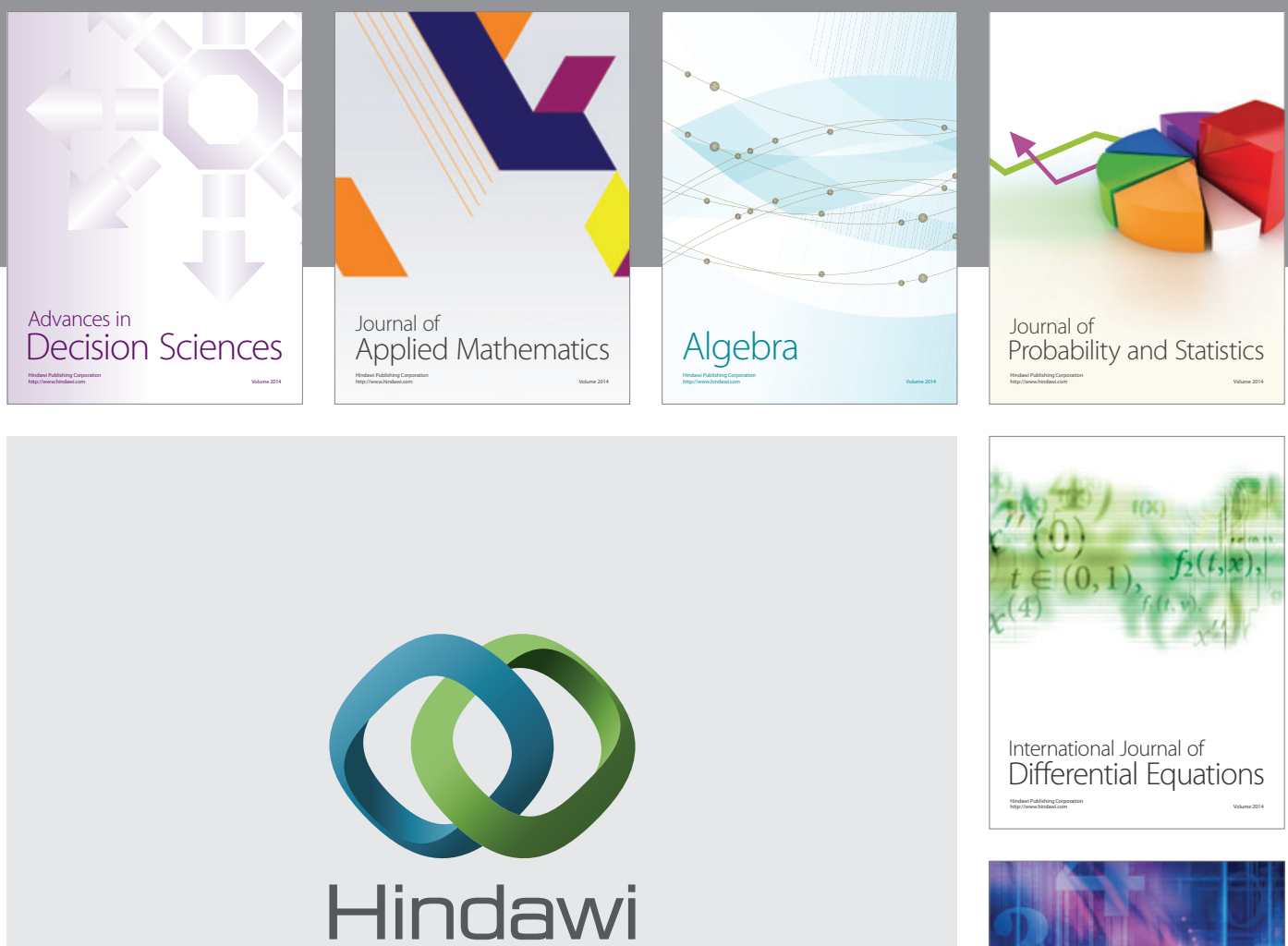

Submit your manuscripts at http://www.hindawi.com
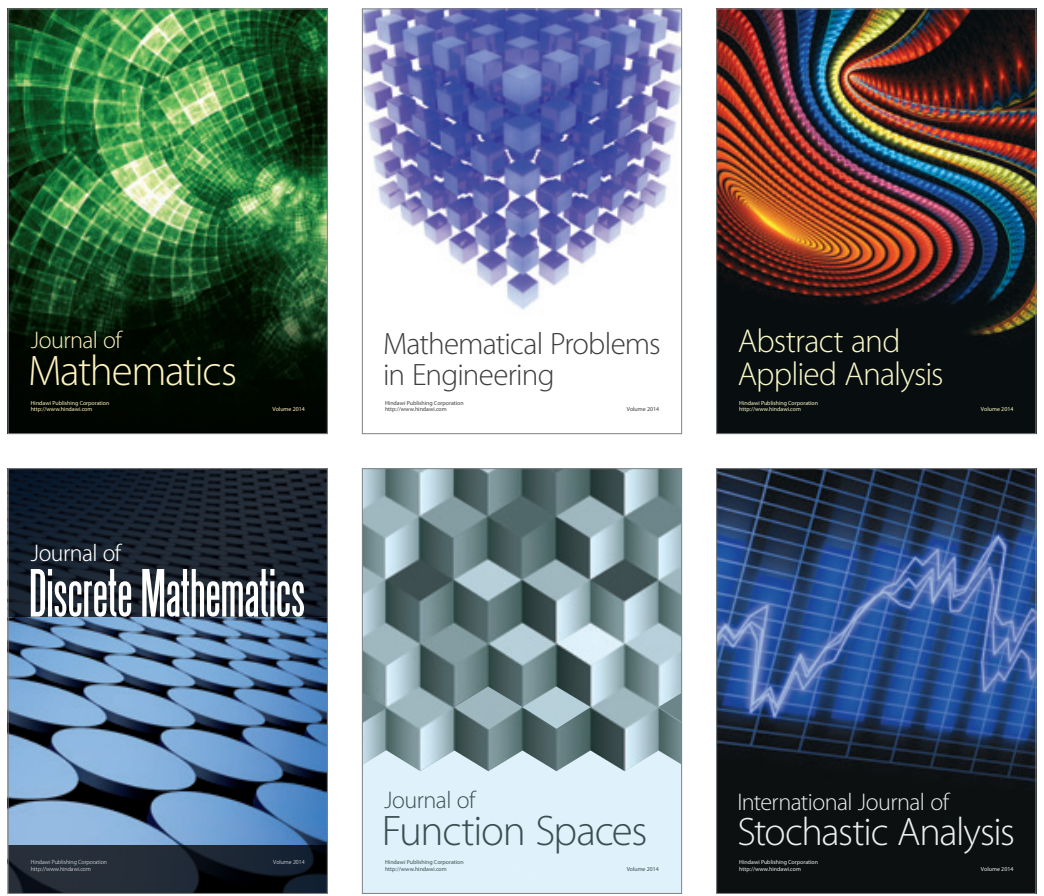

Journal of

Function Spaces

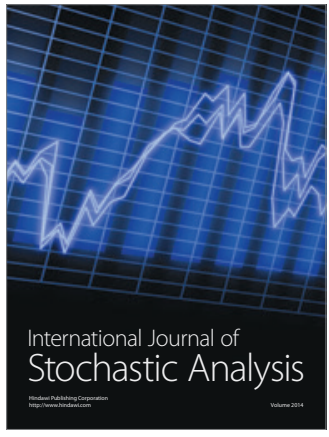

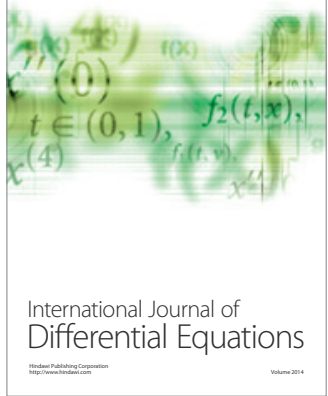
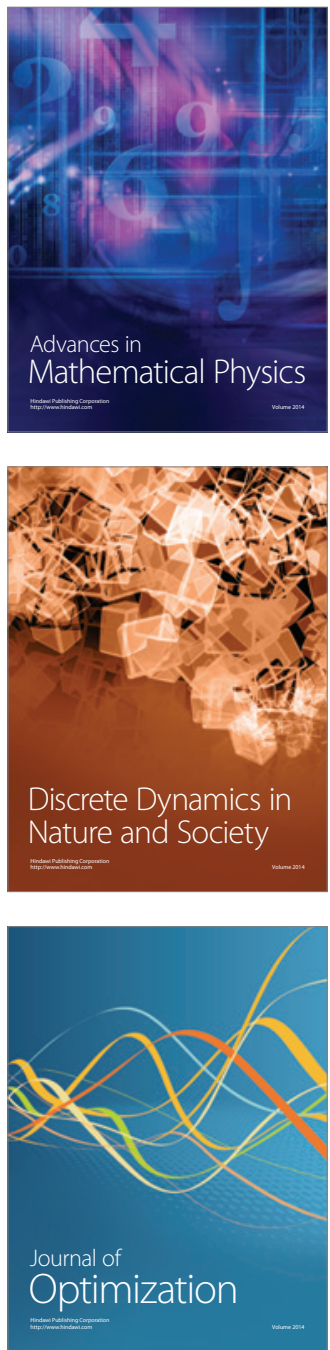